\title{
Özel Eğitimde İnsansı Robotlar
}

\author{
Nihal Şen ${ }^{1 *}$ \\ ${ }^{1 *}$ Bolu Abant İzzet Baysal Üniversitesi, Lisansüstü Eğitim Enstitüsü, Özel Eğitim Bölümü, Bolu, Türkiye, (ORCID: 0000-0002-9511-8401), nihalllsennn@gmail.com
} (Uluslararası Araştırma-Geliştirme ve Tasarım Konferansı - 15-18 Aralık 2021)

(DOI: 10.31590/ejosat.1047564)

ATIF/REFERENCE: Şen, N. (2021). Özel Eğitimde İnsansı Robotlar. Avrupa Bilim ve Teknoloji Dergisi, (32), 832-842.

Öz

Robotlar, insanları ve çevrelerini algılama yeteneğinden, insanların durumlarını ve duygularını rasyonalize etme yeteneğine kadar çeşitli yetenekleriyle eğitim ekosisteminin faydalı bir parçası haline gelmektedir. İnsansı robotlar, insansı görünümleriyle, insan benzeri beden diline ve sosyal sinyalleşme yeteneklerine başka bir boyut ekleyerek eğitimde daha doğal ve sezgisel insan-robot etkileşimi sunmaktadır. Robotların hayatımıza girmesiyle birlikte özellikle insansı sosyal robotlar eğitimde sıklıkla kullanılmaktadır. Eğitimin hemen hemen her kademesinde birçok fayda sunan insansı robotlar son yıllarda özel eğitim alanında da artan bir ilgi görmüştür. Bu makalenin amacı insansı robotların özel eğitimdeki uygulamalarını tanıtmak ve bu uygulamalar hakkında farkındalık yaratmaktır. Kapsamlı bir literatür araştırmasına dayanarak, özel eğitimde sıklıkla kullanılan insansı robotlara yer verilen bu çalışmada ayrıca bu robotların özel eğitim alanında kullanıldığı araştırmaların detaylarına da yer verilmiştir. Çalışma, son yıllarda özellikle otizm spektrum bozukluğu olmak üzere farklı yetersizliklere sahip bireylerin de eğitiminde çok sayıda insansı robotun kullanıldığını ve bu sayının giderek artmaya başladığını göstermektedir. Bu çalışmadaki bilgilerin gelecekte özel eğitimde robotları kullanmayı planlayan eğitimcilere ve araştırmacılara yol gösterici nitelikte olacağı beklenmektedir.

Anahtar Kelimeler: İnsansı robotlar, Eğitim robotları, Robot destekli öğretim, İnsan-robot etkileşimi, Özel eğitim.

\section{Humanoid Robots in Special Education}

\begin{abstract}
Robots are becoming a useful part of the education ecosystem, with abilities ranging from the ability to perceive people and their environment to the ability to rationalize people's situations and emotions. Humanoid robots, with their humanoid appearance, add another dimension to their human-like body language and social signaling abilities, offering more natural and intuitive human-robot interaction in education. With the introduction of robots into our lives, especially humanoid social robots are frequently used in education. Humanoid robots, which offer many benefits at almost every level of education, have received increasing attention in the field of special education in recent years. The purpose of this article is to introduce the applications of humanoid robots in special education and to raise awareness about these applications. Based on a comprehensive literature review, this study, which includes humanoid robots that are frequently used in special education, also includes the details of researches in which these robots are used in the field of special education. The study shows that in recent years, a large number of humanoid robots have been used in the education of individuals with different disabilities, especially autism spectrum disorder, and this number is gradually increasing. It is expected that the information in this study will guide educators and researchers who plan to use robots in special education in the future.
\end{abstract}

Keywords: Humanoid robots, Educational robots, Robot-assisted teaching, Human-robot interaction, Special education.

\footnotetext{
*Sorumlu Yazar: nihalllsennn@gmail.com
} 


\section{Giriş}

İnsanoğlu geçmişten günümüze kadar hayatını kolaylaştıran icatların peşinden koşmuştur. Dünya teknoloji tarihi, tekerleğin icadıyla başlayan, su ve buhar gücüyle devam eden endüstriyel devrimlerin ardından gelen dijitalleşmeyle beraber çok uzun bir yol kat etmiştir. Dijitalleşmenin gelişimiyle bilgi teknolojilerine, siber-fiziksel sistemlerin devreye girişine ve en sonunda insanrobot etkileşimine kadar birçok alanda ilerlemeler kaydederek günümüze kadar gelmiştir. Bu teknolojik evrelerin en popüleri ve günümüzde birçok habere ve tartışmaya konu olanı kuşkusuz ki robotlardir.

Robotların geçmişi yeni gibi görünse de 'robot' kelimesi, ilk kez 100 yıl kadar önce Çek yazar Karel Capek'in bir oyununda ifade ettiği, Çek dilinde 'köle (serf) veya işçi (laborer)' anlamına gelen 'robota' kelimesinden üretilerek kullanılmıştır (Hockstein ve ark., 2007). Isaac Asimov, 1938 ve 1942 yılları arasında yayınlanan kısa öyküler koleksiyonunda robotiğin popülerleşmesine katkıda bulunmuştur (Hockstein ve ark., 2007). O zamanlar sadece oyunlarda ve öykülerde geçen robotlar gerçek dünyaya ilham vermiştir. Bilim kurgudan gerçeğe geçiş, General Motors'un otomobil üretimine yardımcı olması için Unimate'i tanıttığ 1958 yılında gerçekleşmiştir. Unimate'in 1961'de montaj hattında ilk kullanımından bu yana, robotiklerin endüstriye uygulanması patlama göstermiştir. Günümüzde ise robotlar, çevreleriyle etkileşime geçebilmek için algılama, öğrenme, planlama ve eyleme geçme yeteneği olan makineler olarak adlandırılabilir (Ghallab ve Ingrand, 2020). Ancak robotun tek ve basit bir tanımı olmamakla birlikte, her makine de robot değildir. Robotlar sensörler aracılığıyla algılar, veri toplar, kontrolünü sağlayarak karar verir ve hareketi gerçekleştirir. Robotlar endüstri, tıp ve sağlık, eğlence, tarım ve hayvancılık ile ulaşım alanlarının yanı sıra özellikle son yıllarda eğitimde de kullanılmaktadır.

On yıldan fazla bir süredir robotların eğitimdeki uygulamaları kapsamlı bir şekilde araştırılmış ve cesaret verici bulgular ortaya çıkmıştır (Curto ve Moreno, 2016; Johnson, 2003; Miller ve ark., 2008). Anaokulundan üniversiteye kadar her kademede kullanımına rastlanan robotlar eğitimde önemli bir yere sahip olmaya başlamıştır. Özellikle sosyal ve insansı robotların eğitimde büyük etkilerinin olması beklenmektedir. Eğitimde kullanılan robotlar, çocukların öğretim ortakları, eğlenceli eğitim araçları, eğitimin tamamlayıcıları, öğretmenler üzerindeki yükü azaltan öğretim yardımcıları ve çocukların çalışmaları için aracılar olarak görülmüştür (Alimisis ve Kynigos, 2009; Belpaeme vd., 2018; Edwards ve ark., 2018; Mubin ve ark., 2013).

Robotların eğitimde kullanılmasının etkilerini araştırmak için karşılaştırmalı çalışmalar yapılmıştır (Kandlhofer ve Steinbauer, 2014). Karşılaştırmalı bir çalışma (Westlund ve ark., 2015), çocuklara yeni kelimeler öğretme bağlamında, çocukların robotla öğrenmeyi tercih ettiklerini ve robotu bir tabletten çok bir insan gibi gördüklerini göstermektedir. Yapılan başka bir çalışmada (Han ve ark., 2008) geleneksel medyanın etkileri (ses band destekli öğrenme ve web tabanlı öğrenme içeren kitaplar) ile evde robot destekli öğrenmenin çocuklar üzerindeki etkileri arasında bir karşılaştırma yapılmıştır. Diğer öğrenme programlarıyla karşılaştırıldığında, ev robotunun çocukların konsantrasyonunu artırmada ve geliştirmede daha etkili olduğu görülmüştür. Alan yazında yer alan farklı çalışmalar da sosyal insansı robotların olumlu etkisini göstermektedir. (Kanda ve ark., 2012; Alemi ve e-ISSN: 2148-2683 ark., 2015). Ayrıca insans1 robotlar, daha insansı sosyal sinyaller sağlamak için beden dili ve yeteneklerine sahiptir; bu tür robotlar daha ilgi çekici olabilir (Chang ve ark., 2010). Bütün bunlar etkileşimi daha doğal hale getirmekte ve işaret dili öğretmek gibi ek yetenekler kazandırmaktadır (Köse ve ark., 2015).

Robotların eğitim alanında birçok çalışmada yer alması bu çalışmalar üzerine yapılan inceleme ve derleme çalışmalarının artmasına neden olmuştur. Özellikle son yıllarda bu konuda yapılmış birçok derleme çalışması yer almaktadır (Belpaeme ve ark., 2018; García-Peñalvo ve ark., 2019; İsmail ve ark., 2019; Kubilinskienè ve ark., 2017; López-Belmonte ve ark., 2021; Yolcu ve Demirer, 2017). Bu çalışmaların yanı sıra eğitimde kullanılan robotların özellikleri üzerine de bazı çalışmalar bulunmaktadır (Pachidis ve ark., 2018). Önceki çalışmalar genel olarak eğitimin her alanında kullanılan robotlara ve bu alanlarda uygulanan çalışmalara odaklanmıştır. $\mathrm{Bu}$ çalışmalar robotların eğitime olan katkılarını gösterme potansiyeline sahip olsa da, robotik uygulamalarının özel eğitim bağlamında ne derece yer bulduğunu gösteren çok az sayıda çalışmaya rastlanmıştır (İsmail ve ark., 2019; Papakostas ve ark., 2021). Özel gereksinimli bireylerin eğitimlerinin diğer bireylerden farklılıklar içermesi bu alanda kullanılacak robotların da farklılaşmasına sebep olmuştur. Literatürde robotik teknolojisinin bir öğretim aracı olarak ya da öğretime yardımcı olarak özel eğitimde kullanımını ele alan ve bu robotları detaylı bir şekilde tanıtan bir çalışma bulunmamaktadır. $\mathrm{Bu}$ çalışmanın amacı özel eğitimde kullanılan robotların neler olduğu ve ne tür yararları olduğu konusunda araştırmacı ve uygulamacilara bilgi sunmaktır. Bu spesifik alanda kullanılabilen robotların bir arada sunulmasının hem eğitimciler hem de veliler olmak üzere özel eğitimdeki birçok paydaş için yararlı olacağ 1 düşünülmektedir. Ayrıca özel eğitim alanında ileride yapılacak olan robotik uygulamalarına da yol göstermesi beklenmektedir. $\mathrm{Bu}$ çalışmada ilk olarak eğitimde kullanılan insansı robotlara daha sonra da özel eğitimde kullanılan insansı robotlara yer verilmektedir.

\section{Eğitimde İnsansı Robotlar}

Teknolojik gelişmeler hayatımızın her yönünü etkilemeye devam etmektedir. Teknolojinin etkileri o kadar büyüktür ki, onlara ayak uydurmaktan başka seçeneğimiz bulunmamaktadır. Teknolojinin ilerlemesiyle hayatımıza giren robotlar toplumumuzun ayrılmaz bir parçası haline gelmiştir ve bir eğitim teknolojisi olarak kullanılma konusunda büyük potansiyele sahiptir. $\mathrm{Bu}$ da eğitim konusunda bildiğimiz bazı kalıpları y1kabilmektedir. Örneğin eğitim öğretim süreci var oldukça kurulan "Bir öğretmenin ihtiyaç duyduğu her şey bir sınıftır ve bazı öğrencilerdir" şeklindeki eski inanç artık geçerli bir paradigma değildir. Robotların eğitim alanında kullanımı oldukça yeni olmasına rağmen, bazı uzmanlar önümüzdeki on yıl içinde dünya çapında sınıflarda düzenli olarak kullanılacağını tahmin etmektedir. Araştırmacılar, robotların insan öğretmenlerin yerini alamayacağını, ancak robotların teşvik edici, ilgi çekici ve öğretici bir öğretim yardımcısı olarak sınıfa getirebileceğini vurgulamaktadır (Mubin ve ark., 2013).

Robotik alanındaki çalışmalar son yıllarda insana benzeyen ve kullanıcıları ile doğal bir şekilde etkileşime giren insansı robotların geliştirilmesine olanak sağlamıştır (Chin ve ark., 2011). Chin ve ark., (2011)'e göre insans1 robotlar, insanların dikkatini çekmek ve onlarla sosyal olarak anlamlı şekillerde etkileşime geçmek için fiziksel bir bedene sahip yeni bir robot türüdür. Alkhalifah ve ark., (2015)'e göre insansı robot, insan vücudunun 
genel yapısına dayanan bir robot türüdür, iki bacaklı ve iki kollu insanlar gibi yürür, bir üst gövdesi vardır ve bir kafası olabilir. Gelişmiş sosyal becerilere sahip olmalarının yanı sıra yüz ifadeleri, jestler ve tonlamalar yoluyla duygu ifade etmeye ve uygun beden diliyle yanıt vermeye programlanmıştır (Lin ve ark., 2011). İnsansı robotların özellikle eğitim olmak üzere eğlence, güvenlik, yaşlı bakımı, rehberlik vb. birçok etkileşim alanında da rol oynamaları beklenmektedir.

İnsans1 olmayan basit robotlara nazaran insansı robotların eğitimde kullanılmasının birçok avantajı vardır (Pandey ve Gelin, 2017). Bu nedenle her geçen gün daha fazla çalışma, bir sınıfta öğretme ve öğrenmeyi desteklemek için insansı robotları kullanmaya başlamıştır. İnsansı robotların eğitimde kullanılmasına yönelik çalışmaların incelendiği bir çalışmada insansı robotların eğitimde farklı roller alabileceği belirtilmiştir (Tuna ve ark., 2019). Bunlar arasında öğretmenin yardımcısı, öğrencilerin arkadaşı, akranı ve öğretim ortağı, eğlenceli bir öğretim yöntemi, uzaktan eğitime yardımcı olmak ve öğretim için bir platform/araç görevi görmek gibi farklı roller sayılabilir.

Genel olarak bakıldığında öncelikle insansı robotlar eğitimde öğretmenlerin yardımcısı olarak kullanılabilir. Özellikle devlet okullarında, öğrencilerin sayısı giderek artmakta ve öğrenci başına düşen öğretmen sayısı azalmaktadır. Modern pedagoji yöntemleri öğrencilerle etkileşimi gerektirdiğinden dolayı öğretmen öğrenciyle bireysel bilgi alışverişine daha fazla zaman harcamalıdır. Genel olarak dijital asistanlar ve özellikle insansı robotlar bu soruna potansiyel bir çözüm olabilir. Robotlar, yabancı dilde iletişim kurmak, bir şiir okumak veya bir çarpım tablosunu kontrol etmek için öğrencilerle bireysel olarak etkileşime girebilir. Robotun daha ulaşılabilir olacağı gerçeğinin ötesinde, bir robotun önünde hata yapmaktan daha az korkması öğrenciler için daha avantajlı bir durumdur. $\mathrm{Bu}$ argümanlar, eğitim için kullanılabilecek dijital cihazların çoğu için geçerlidir, ancak insansı bir robot şeklindeki düzenleme, öğrenciyi, öğretimin verimliliğini arttırması umulan fiziksel bir etkileşime dahil etmektedir (Chin ve ark., 2011).

Robotlar, öğrencilere çalışmalarında eşlik edebilir, yapılması gereken egzersizi hatırlatabilir; derslerde yardımcı olabilir ve öğrenciyi bu konuda sorgulayabilir. Yapılan bir araştırmada (Kanda ve ark., 2004) iki insans1 robot, Robovie, 2 hafta boyunca bir ilkokulun koridoruna konulmuştur. Teneffüs sırasında çocuklar her iki robotla da etkileşime girmek için serbest bırakılmıştır. Bulgular, bu tür bir etkileşimin bazı çocukların İngilizcelerini geliştirmeye teşvik ettiğini ve robotun düşük düzeyde İngilizce bilen çocukların ilgisini çekmede daha başarılı olduğunu göstermiştir. Araştırmacılar, bu bulguları sosyal psikolojideki önceki literatüre dayandırarak insan ve robot arasında benzerlik ve ortak zemine sahip olmanın etkileşimi ve öğrenmeyi artırdığını öne sürmüştür.

Robotlar, çocukların akranları ve öğretim ortaklarıdır. Bilgisayar tabanlı öğrenme tekniklerinde, öğrencilerin öğrenmesine yardımcı olmak için bir bilgisayar aracını öğretme sosyal metaforunu kullanan öğretilebilir aracılar kavramı vardır (Chase ve ark., 2009). Öğretilebilir aracılarla etkileşim sırasında, sorumluluk duygusu da dahil olmak üzere sosyal tutumlar, öğrencileri anlayışlarını organize etmek için daha çok çalışmaya motive eder. Öğretilebilir aracıların, çocukların muhakeme yeteneklerini geliştirdiği bulunmuştur. Robotikte, bu fikir, insan öğreniciden (çocuklardan) talimatları alan robotun, öğretme yoluyla öğrenme etkisi elde etme varsayımıyla birlikte öğrenme senaryosu bağlamında araştırılmıştır (Tanaka ve Matsuzoe, 2012).
$\mathrm{Bu}$ araştırmaya göre, birlikte öğrenen robot insan öğretmenler tarafindan yönlendirilen sınıf etkinliklerinde kullanılırsa, çocukların öğreterek öğrenmesini teşvik etmek ve geliştirmek için olumlu etkiler gösterebileceği rapor edilmiştir. Ayrıca öğretmenlerin, dikkati dağılmış çocukların ilgisini çekmek ve onları öğrenme etkinliğine geri getirmek için bu tür "bakım alan" robotları kullanabileceğine dikkat çekmiştir.

Robotlar eğlenceli bir öğretim yöntemi olarak kullanılabilir. Beden dili ve çok modlu etkileşim yetenekleri ile insansı robotlar, çocukları etkileşimin öğrenme tarafina yönlendirirken aynı zamanda eğlendirebilir. Örneğin sınıflarda hikaye anlatan robotlar, etkileşime girmek ve eğlendirmek için daha iyi bir platform olarak gösterilmektedir (Chang ve ark., 2010). Ayrıca robotlarla etkileşimli eğitici oyunlar geliştirmeye yönelik çalışmalar da bulunmaktadır. Yapılan bir araştırmada (Deshmukh ve ark., 2015), Nao Torso robotu, dokunmatik ekranlı bir cihazda oyun benzeri bir senaryo ile 11-13 yaşındaki öğrencilere harita okuma becerilerini öğretmek için kullanılmıştır. Tasarlanan görevlerin, öğrencinin harita okuma için yönler, mesafe ve harita sembolleri hakkında bir anlayış geliştirmesine yardımcı olmuştur.

Birçok durumda, çeşitli nedenlerle (örn. fiziksel sorunlar, enfeksiyon riski, aile ihtiyaçları vb.) bir öğrenci derslere fiziksel olarak katılamayabilir. Derslerin çoğunun dijitalleştirilmesi bu durumda önemli bir gelişmedir; öğrenci okulda neler olup bittiği hakkında e-posta ile bilgilendirilebilir. Ancak uzun bir süre sınıf yaşamına katılımın olmaması, öğretmenler ve diğer öğrencilerle etkileşimin olmaması, eğitim ortamına uzak olan öğrencinin katılımını azaltabilecek bir durum haline gelebilir. Telepresence bu sorun için teknik bir çözümdür. Basit bir video konferans sistemi (örn. Skype) sayesinde öğrenci sınıfa entegre olabilir ve orada neler olduğunu görebilir ve dinleyebilir. Ancak sınıfta basit bir ekran olmak kısıtlayıcıdır: uzak öğrenci kendi bakış açısını seçemez (öğretmene veya araya giren başka bir öğrenciye bakarak) ve dikkat çekmek için elini kaldıramaz. İnsansı bir robotu sinıfta avatar olarak kullanmak, uzaktaki öğrencinin varlığını taklit etmek için nihai çözüm olabilir.

İnsans1 robotlar, öğretim için bir platform/araç görevi görebilir. Örneğin, Nao robotu bu tür eğitim amaçları için yaygın olarak kullanılmaktadır (https://www.ald.softbankrobotics.com/en/solutions/educationresearch). İnsansı robotlar ayrıca sınıfta kodlama ve yapay zeka öğretimine yardımcı olmak için kullanılabilir (https://www.sciencealert.com/robots-are-about-to-enteraustralian-schools-as-part-of-a world-first-study). Robotiğin öğretimdeki ilk tanıtımlarından biri robotik ve teknolojik derslere yönelik olmuştur.

Daha genel bir şekilde, insansı bir robotun davranışını programlamak, insan vücudunun karmaşıklığını ve fiziksel ve bilişsel kontrolünü gerçekleştirmek için bir firsattır. Yapay zeka, insanların hayalinde, genel olarak robotik ve özel olarak insans1 robotik ile güçlü bir şekilde bağlantılıdır. Bir robot insan gibi göründüğünde, zeka ve insani diyalogla insan gibi davranması beklenir. Öğrencilerin denediği ilk zeka uygulamaları genellikle engellerden kaçınma ve diyalogdur. İnsansı bir robot aracılığıyla sözlü bir diyalog kurmak, dilimizin altında yatan gürültülü ortamlardaki otomatik konuşma tanımadan, aynı şeyi söylemenin birçok yolundan geçen cümlelerimizde saklı olan bilgiye, farklı dil seviyelerine ve belirsizliğin yönetimine kadar birçok karmaşıklığı algılamayı kolaylaştırır. Robotik genel olarak dilbilgisi, sözdizimi, göstergebilim ve aynı zamanda robotun 
kullanıcının duygularını yönetmesi gerektiği anda psikolojinin yönlerini öğretmek için bir araç olabilir.

Robotlar inanılmaz derecede değerli öğretim araçları olabilir, ancak mümkün olan en iyi sonuçları elde etmek için onları doğru şekilde uygulamak önemlidir. İnsansı robotlar eğitimde özellikle matematik ve fen derslerinde daha çok uygulama şansı bulmuş olsa da hemen hemen her alanda öğretime yardımcı araçlar olarak kullanılabilir. İnsansı robotların kullanılabileceği alanlardan birisi de özel eğitim alanıdır. Tuna ve ark., (2019) bir insan öğretmene kıyasla, insansı robotların utangaçlık, hayal kırıklığı, isteksizlik ve özgüvenle ilgili sorunları çözmeye yardımcı olabileceğini ve birçok ülkede, özellikle özel eğitim için yaygın olarak kullanıldığını belirtmiştir. Takip eden kısımlarda insansı robotların özel eğitiminde kullanımına yönelik bilgilere yer verilmektedir.

\section{3. Özel Eğitimde İnsansı Robotlar}

Papakostas ve ark., (2021)'e göre çocuklar şu nedenlerle sosyal robotlarla etkileşime girmeye çok isteklidirler: (1) çocuklar robotlara sadece basit makineler olarak değil, sevimli oyuncaklar olarak da davranırlar; (2) robotlar, birçok interaktif yeteneğe (hareketler, sesler, renkli 1şıklar vb.) sahipken, çocuksu görünümleri nedeniyle çocukların dikkatini çeker; (3) sosyal robotlar, çocuklara bikmadan defalarca tekrar ederek öğretme sabrına sahiptir; ve (4) sosyal robotlar, çocuklarla etkileşimleri sırasında duygusal ve davranışsal olarak kararlıdır. Özel gereksinimli olan çocuklar için de benzer nedenler sayılabilir. Bu tür bireylerin eğitiminin daha hassas süreçler içerdiği düşünüldüğünde özel gereksinimli çocukların eğitiminde insansı robotların faydalı olacağı açıktır. Bununla birlikte insansı robotların özel eğitimde kullanımı, bir veya birden fazla yetersizliği olan çocukların davranış ve becerileri değişiklik gösterdiğinden ek zorluklar içerebilir (Papakostas ve ark., 2021).

İnsans1 robotların özel eğitimde birçok farklı alanda uygulamalarına rastlamak mümkündür (İsmail ve ark., 2019; Papakostas ve ark., 2021). Güncel bir sistematik derleme çalışmasının (Papakostas ve ark., 2021) sonuçlarına göre özel eğitim alanında insansı robotların en çok kullanımına otizm spektrum bozukluğu, işitme yetersizliği, zihinsel yetersizliği ve çoklu yetersizliği olan bireylerde rastlanmıştır. Yapılan başka bir araştırmada (Robins ve ark., 2005), otizm spektrum bozukluğu olan çocuklara sosyal etkileşim yeteneklerini öğretmek için insana benzeyen bir oyuncak bebek robotu kullanılmıştır. Sosyal olarak yardımcı robotların (insansı robotlar dahil) otizm spektrum bozukluğu olan çocukların eğitiminde faydalı olduğu kanıtlanmıştır. Başka bir çalışmada (Barakova ve ark., 2015; Huskens ve ark., 2013), otizm spektrum bozukluğu olan çocuklara sosyal becerileri öğretmek için nasıl soru sorulacak, nasıl proaktif olunacak ve işbirliği yapılacak sorularına yer verilerek insansı robotların rolü incelenmiştir. Bir diğer çalışmada (Taheri ve ark., 2016), sosyal robotlar otizm spektrum bozukluğu olan çocuklara müzik öğretmektedir. Hatta öğretmenlere ve çocuk bakımı çalışanlarına otizm spektrum bozukluğu olan çocukların desteklenmesine yardımcı olmak için tasarlanmış AskNao (https://asknao.aldebaran.com/) gibi ticari çözümler de bulunmaktadır. Nao insansı robotu, özellikle otizm spektrum bozukluğu olan çocukların ihtiyaçlarını karşılamak için eğlenceli ve eğitici bir uygulama yelpazesi içermektedir. Bu tür bir başka platform da otizm spektrum bozukluğu olan çocuklarda sosyal becerileri geliştirmeyi amaçlayan RoboKind adlı robottur (http://www.robokindrobots.com/). Bir araştırmada (Köse ve ark.,
2015), insans1 robot, Robovie R3 ve Nao H25 ile işitme yetersizliği olan çocuklara işaret dili öğretiminde deneyler yapılmıştır. Bu gibi durumlarda insansı robotlar, insan benzeri jest, beden ve işaret dilleri üretmek için bir zorunluluktur. Araştırma sonuçları cesaret vericidir ve bu tür kullanım durumları da insansı robotların potansiyellerini göstermektedir.

Literatürde birçok insansı robot geliştirilmiştir. Bu robotların bir kısmı eğitimde kullanılmaktadır. Eğitimde kullanılan insansı robotların bir kısmı da özel eğitimde kullanılabilmektedir. Takip eden kısımda özellikle özel eğitim alanında kullanılabilen robotlara (Nao, Kaspar, Mindstorms vb.) yer verilmiştir.

\subsection{Nao}

Dünya çapında 70 'den fazla ülkede 6.000 'den fazla akademik kurumda yer alan ve binlerce öğrenci ve öğretmenin ihtiyaçlarını karşılayan Nao en popüler insansı eğitim robotudur. Ayrıca Nao, araştırmalarda en çok kullanılan insansı robottur ve öğrenen robot araştırmalarının yaklaşık \%50'si Nao kullanılarak yürütülmektedir (Papakostas ve ark., 2021). Eğitim endüstrisine odaklanan Nao kusursuz olanaklara sahip programlanabilir bir eğitim aracı olarak inşa edilmiştir. Nao aynı zamanda bir öğretmenin asistanı, öğrencinin arkadaşı, moderatör ve platformdur.

Nao kameralara ve ses kapasitelerine (sentez ve tanıma) sahip iki ayaklı, $58 \mathrm{~cm}$ 'lik insansı bir robottur. Bu özellikler esas olarak, Nao'nun bir çocuğa benzetilerek onlarla yakınlık kurması amacıyla geliştirilmiştir (Mwangi ve ark., 2017). Ayrıca 25 derecelik serbestlik ile yürüme, jestler ve başını eğme gibi insan hareketlerine yakın hareketler yapabilir. Nao küçük nesneleri manipüle edebilir (Masson ve ark., 2016; Tanaka ve Matsuzoe, 2012), öğrenme için yararlı işaretler ve jestler yapabilir (Masson ve ark., 2016; Yadollahi ve ark., 2018) ve jestleri veya işaretleri taklit edebilir (Akalın ve ark., 2013). Nao'nun cümleleri yüksek sesle söylemesini ve çocukla sözlü olarak konuşmasını sağlayan bir konuşma sentez modülü vardır (Van Der Drift ve ark., 2014). Ek olarak, sesinin hızı ve tonu kolayca ayarlanabilir, bu da özellikle öğreterek öğrenmede, örneğin okumayı öğrenmede yararlıdır. Yüz ifadelerinden yoksun olmasına rağmen Nao, iCat gibi bu yeteneğe sahip bir robot kadar duyguları (öfke, korku, sevinç, üzüntü ve şaşkınlık) ifade edebilmektedir (Mwangi ve ark., 2017). Nao'nun duyguları simüle etme yolu, vücut hareketleri ve göz çevresindeki LED'ler (yanıp sönen ve renk değiştiren) aracılığıyladır. Bu nedenle, Nao'nun yüz ifadesinin olmaması, çocuğun hissettiği yakınlığa engel değildir.

Nao otizm spektrum bozukluğu, dikkat eksikliği ve hiperaktivite bozukluğu, dil ve konuşma bozukluğu, zihinsel yetersizliği ve işitme yetersizliği olan bireyler için etkili kapsayıcı uygulamaları gerçekleştirmek ve bireyselleştirilmiş eğitim programı ile eğitimi teşvik etmek için halihazırda kullanılmaktadır (Lewis ve ark., 2016; Lytridis ve ark., 2018; Rakhymbayeva ve ark., 2020; Silvera-Tawil ve ark., 2018; Taheri ve ark., 2019; van den Heuvel, 2017). Ayrıca Nao özel gereksinimli bireylerle kolayca empatik bağ kurabilir ve onlara fiziksel ve entelektüel egzersizler için ilham vererek yönlendirebilir. Nao, utangaçlık ve isteksizlik gibi olumsuz duyguları azaltarak özel gereksinimli bireylerin sosyal becerilerini ve özgüvenlerini artırmak adına da yardımcı olmaktadır. 


\subsection{Kaspar}

Sosyal bir robot olan Kaspar (Kinesics And Synchronisation in Personal Assistant Robotics), önde gelen uluslararası robotik araştırma ekibi Hertfordshire Üniversitesi'nin Adaptive Systems araştırma grubu tarafından tasarlanmış ve geliştirilmiştir. 1998 yılında, Profesör Kerstin Dautenhahn ve ekibi, dış dünyayla etkileşim veya iletişim kurmakta zorlanan otizm spektrum bozukluğu olan çocuklar için terapötik oyuncaklar olarak kullanılmak üzere robotlar geliştirmeye ve araştırmaya başlamıştır. Bu çalışma üzerine inşa edilen Kaspar projesi 2005 yılında başlatılmıştır (Wood ve ark., 2021).

Kaspar, otizm spektrum bozukluğu ve diğer iletişim güçlükleri olan çocukların yaşamlarını iyileştirmek için sosyal bir arkadaş olarak tasarlanmış insansı bir robottur (Wood ve ark., 2021). Bu robot çocuk boyutunda ve ten rengi bir yüze sahiptir. Robotun herhangi bir yaşa veya cinsiyete özel olmayan nötr bir ifadesi vardır, bu nedenle çocuklar Kaspar'ı istedikleri gibi yorumlayabilmektedir. Yetişkinler için Kaspar güzel görünmeyebilir, ancak gerçekçi, insana benzer, ancak basitleştirilmiş özellikleri otizm spektrum bozukluğu olan çocuklara hitap etmektedir. Etkileşimde bulunarak ve çocuksu bir şekilde davranarak Kaspar, öğretmenlerin ve ebeveynlerin otizm spektrum bozukluğu olan çocukları sosyalleşme ve başkalarıyla iletişim kurmada karşılaştıkları zorlukların üstesinden gelmeleri için desteklemelerine yardımcı olmaktadır.

Kaspar, sosyal etkileşimi çocuk için daha basit ve daha rahat hale getirmeyi amaçlayan, daha öngörülebilir ve başlangiçta tekrarlayan bir iletişim biçimi sunan etkileyici bir robot olarak bilinçli olarak tasarlanmıştır. Otizm spektrum bozukluğu olan çocuklara erken müdahalenin bir çocuğun gelişim yörüngesi üzerinde önemli bir etkisi olduğuna dair artan kanıtlar arasında, araştırmacılar Kaspar ile etkileşimin otizm spektrum bozukluğu olan çocukların diğer insanlarla daha özgürce iletişim kurmasına ne ölçüde yardımcı olacağını araştırmaya başlamışlardır. Araştırmalar, Kaspar'ın otizm spektrum bozukluğu olan çocuklar için güvenli ve öngörülebilir bir öğrenme aracı olabileceğini göstermiştir (Iacono ve ark., 2011; Wood ve ark., 2021) 2016 y1lında International Journal of Social Robotics adlı dergide yayınlanan bağımsız bir araştırma, otizm spektrum bozukluğunda 54 uygulayıcıdan oluşan bir grubun Kaspar'ın bu çocuklar için çok çeşitli terapi ve eğitim hedeflerine yönelik müdahalelerde yararlı olabileceğine inandığını bulmuştur (Huijnen ve ark., 2016).

\subsection{Lego Mindstorms}

Lego Mindstorms, Lego yap1 taşlarına dayalı programlanabilir robotların geliştirilmesi için Lego tarafindan üretilmiş bir donanım ve yazılım yapısıdır. Sistemin her versiyonu, sistemi kontrol eden bir bilgisayar Lego tuğlası, bir dizi modüler sensör ile motor ve mekanik sistemleri oluşturmak için Technic serisinden Lego parçaları içermektedir. Tasarımı nedeniyle robot, insansı olmayan (araç) veya insansı bir robot olabilir.

Yaratılışından bu yana Mindstorms platformunun beş nesli olmuştur: orijinal Robotics Invention System, NXT, NXT 2.0, EV3 ve Robot Inventor kiti. Her platform sürümüyle birlikte motor ve sensör özellikleri genişlemiştir. Son sistem olan Lego Mindstorms EV3, 2013 yılında piyasaya sürülmüştür. FIRST Lego Ligi ve Dünya Robot Olimpiyatı gibi bazı robot yarışmaları bu seti kullanmaktadır. Çoğu durumda belirli setler; otizm spektrum bozukluğu, zihinsel yetersizlik, fiziksel yetersizlik ve e-ISSN: 2148-2683 çoklu yetersizlik gibi çeşitli engelleri olan çocuklarla yapılan çalışmalarda uygulanan robotları oluşturmak için kullanılmıştır (Papkostas vd., 2021). Ayrıca alan yazında yapılan araştırmalarda Lego Mindstorms'un fiziksel ve zihinsel yetersizliği olan bireylerin bilişsel, fiziksel ve sosyal ihtiyaçlarını karşılamaya yardımcı oldukları görülmektedir (Lindsay ve Hounsell, 2017). Başka bir araştırmada Lego Mindstorms'un otizm spektrum bozukluğu ve zihinsel yetersizliği olan bireylerin sosyal becerilerini geliştirdikleri vurgulanmıştır (Costa ve ark., 2010).

\section{4. iRobiQ}

iRobiQ, okul öncesi çocukların eğitiminde kullanılan, internet bağlantısı sayesinde uzaktan, içinde bulunduğu mekanın kontrol edilebilmesini sağlayan, kullanıcılarını tanıyan, onlarla iletişime geçebilen bir robottur. iRobiQ'nun maksimum hızı 45 $\mathrm{cm} / \mathrm{sn}$ 'dir; kolları için bir derece, kafası için iki derece serbestlik vardır. Ayrıca bu robot öfke, korku, iğrenme, üzüntü, mutluluk ve şaşkınlık arasında değişen duygusal yüz ifadeleri üretebilir. Robot üzerinde çeşitli konumlarda altı adet dokunmatik sensör bulunmaktadır; kafası, kolları ve tekerleklerinin her birinde iki sensör bulunur. $\mathrm{Bu}$ robotun kızılötesi ve tampon sensörleri bulunmaktadır ve gövdesi 10 inçlik bir dokunmatik ekrana sahiptir. iRobiQ, yüz ve görüntü tanıma motoruna sahiptir, işaretleyici tabanlı artırılmış gerçeklik teknolojisini kullanır ve 200 kelimenin \%80'ini tanımak için İngilizce ve Korece metinden konuşma yapabilir (Lee ve Hyun, 2015).

iRobiQ robotu tasarımının daha çok otizm spektrum bozukluğu olan çocuklara yönelik olduğu ve robotun kendisinin iletişim ve sözdizimsel becerileri veya bunlarla yakından ilişkili diğer becerileri geliştirmeyi amaçlayan etkileşimler bağlamında kullanıldığı görülmektedir. Çoğu durumda robot, çocuklara yönergeler veya diğer yardımcı ipuçları sağlayarak öğretmenlerle çocuklar arasındaki etkileşim sırasında öğretmenlere yardımcı olmak için bir araç olarak kullanılmıştır. Ayrıca, bir kart oyunu oynayarak ve oyun sırasında yardım ve geri bildirim sağlayarak otizm spektrum bozukluğu olan çocuklara dikkat, iletişim ve sosyal becerileri öğretmek için kullanılmıştır (Jordan ve ark., 2013).

\subsection{Alice}

Sosyal robot Alice yaşlı bireylere yönelik tasarlanan sosyal robot projesidir. Profesör Johan Hoorn ve araştırma ekibi, yaşlıların daha az yalnız hissetmelerine yardımcı olan robot kız robotik araştırma projesi "Alice” ile 2020 Huibregtsen Ödülü'nü kazanmıştır. Yaşlanan toplumlarda yalnızlığın büyük bir sorun olduğunu fark eden Profesör Hoorn, Amsterdam Vrije Üniversitesi'nden Profesör Elly Konijn ile yapay zekayı uzaktan kumandalı işlevlerle birleştiren Alice'i geliştirmek için çalışmıştır. Elektromekanik bir torun görevi gören Alice, yaşlıların yoldaşı olarak, onlarla sohbet ederek ve söylediklerine empatik yanıtlar vererek yalnızlıklarını gidermeye ve yaşlıların yaşam kalitelerini yükseltmeye yardımcı olmaktadır.

Alice, yaşlılara bakanlara yardım eli ve yaşlı yetişkinlere dost olarak yalnızlığı gidermeyi ve yaşlıların yaşam kalitesini iyileştirmeyi amaçlamaktadır. Robot Alice, bu hedef grubun ihtiyaçlarına mükemmel bir şekilde yanıt vermek için yaşlı kullanıcılarla birlikte geliştirilmiştir. Alice, yaklaşan etkinliklerini hatırlatarak veya akrabalarına ve arkadaşlarına telefon ederek yaşlıların gününü düzenleyebilir. Bunlar, yaşlıları harekete geçmeye motive eden işlevsellik örnekleridir, ancak 
Alice daha pasif bir şekilde de destek sunabilir. Sosyal bir varlık olarak kullanıcıya 'dinleyici' olarak hizmet edebilir ve ona kişisel sorular sorabilir. Ayrıca ev çok sessizleştiğinde en sevdiğiniz şarkıyı çalar, size havanın nasıl olacağını söyler ve günlük haberleri okur.

Alice yaşlıların yanı sıra otizm spektrum bozukluğu olan bireylere yönelik de kullanılmıştır. Robotların konuşma, hareket ve yüz ifadeleri yeteneklerini kullanarak otizm spektrum bozukluğu olan bireylerin taklit ve ortak dikkat becerilerini geliştirdiği alan yazında vurgulanmaktadır (Pour ve ark., 2018; Taheri ve ark., 2014; Taheri ve ark., 2018).

\subsection{Probo}

Probo, özellikle çocuklara odaklanarak bilişsel insan-robot etkileşimini incelemek için araştırma platformu olarak geliştirilen akıllı bir kucaklama robotudur. Robot Probo, insan benzeri sosyal ipuçlarını ve iletişim yöntemlerini kullanırken doğal bir etkileşim sağlayan sosyal bir arayüz görevi görecek şekilde tasarlanmıştır. Robot, yüz ifadelerini gösterebilen, 20 derece serbestlik içeren tam olarak çalıştırılan bir kafaya sahiptir. Dikkat çekici başka bir özelliği de, hareketli bir bagaj kısmı ile yumuşak ve sarılabilir cekete sahip olmasıdır.

Probo tıp, sosyal, psikoloji ve eğitim alanlarında destekleyici bir araştırma rolü oynayabilmesi için bilim camiasına erişilebilir hale getirilmiştir. $\mathrm{Bu}$ robot otizm spektrum bozukluğu olan çocuklarla yapılan çalışmalarda kullanılmıştır (Pop ve ark., 2013; Simut ve ark., 2016). Alan yazında yer alan bir çalışmada sosyal bir robot olan Probo'nun, otizmli çocukların sosyal ve duygusal becerilerini geliştirdiği, duyguları tanımlamadaki performanslarını artırmada yardımcı olduğu belirtilmiştir (Pop ve ark., 2013). Alan yazında yer alan bir diğer çalışma otizm spektrum bozukluğu olan çocuklarda robot destekli terapi için bir terapiste yardım sağlamada sosyal robot Probo'nun rolünü incelemeyi amaçlamaktadır (Vanderborght ve ark., 2012). Bu çalışma, belirli durumlarda, otizm spektrum bozukluğu olan çocukların sosyal performanslarının, sosyal hikaye anlatımı için bir araç olarak robot Probo kullanıldığında, bir insan okuyucunun hikayeleri anlattığı zamana göre arttığını göstermektedir.

\subsection{Zeno}

Zeno tıpkı biz insanlar gibi, fiziksel eylem ve tepkileri belirlemek ve kontrol etmek için çevresinin 3 boyutlu zihinsel görüntüsünü görebilir. Daha sonra çevresinde gördüklerine göre gezinme, yüz ifadeleri yapma ve vücudunu hareket ettirme yeteneğine sahiptir. Hanson Robotic ekibi ayrıca, Zeno'nun hem konuşmayı hem de yüzleri tanıyıp hatırlayabilmesi ve buna göre etkileşim kurabilmesi için konuşma tanıma ve dil muhakemesi için konuşma yapay zekasına sahip bir karakter motoru oluşturmuştur. 2007'de Wired NextFest'te tanıtılan robot, bacaklarında, gövdesinde, kollarında ve yüzünde 28 'den fazla yerleşik özel motorla çok çeşitli hareket yeteneğine sahiptir. Esnek yüzüyle duygularını gösterebilen, çevik ve kendi kendini dengeleyen vücuduyla gösteriler yapabilen akıllı bir karakter robotudur. Uzanabilir, ayağa kalkabilir, kollarıyla hareket edebilir, gülümseyebilir, göz teması kurabilir, gözlerini ve ağzını açıp kapatabilir. ASIMO'dan farklı olarak sistem otonom değildir, ancak standart bir ev bilgisayarı aracılığıyla kablosuz olarak kontrol edilir.

Zeno özellikle otizm spektrum bozukluğunun teşhis ve tedavisinde insan-robot etkileşimi araştırmalarında kullanılan bir platform olarak tasarlanmıştır. İlk defa 2007 yılında geliştirilen
Hanson Robotics'in 17 inçlik Zenohumanoid'i artık dünya çapında otizm araştırmalarında yaygın olarak kullanılmaktadır. Zeno ile konsantrasyonu ve farkındalığı geliştirmek, olumsuz davranışları ve stresi azaltmak, iletişim becerilerini geliştirmek ve daha fazla sosyal etkileşim sağlamak amaçlanmaktadır (Palestra ve ark., 2016; Silva ve ark., 2018).

\subsection{CommU ve Sota}

Osaka Üniversitesi'nde, Hiroshi Ishiguro ve Yuichiro Yoshikawa tarafindan iki tür Sosyal Konuşma Robotu "CommU: Communication Unity" ve "Sota: Social Talker" geliştirilmiştir. Son zamanlarda yapılan robotik araştırmalarında, insanlarla konuşabilen robotlar giderek daha fazla dikkat çekmektedir. Ancak, sohbet katılımcılarına diğer insanlarla günlük konuşmalarında sahip oldukları bir konuşma hissi verebilen robotlar henüz geliştirilmemiştir. Bu araştırma grubu, "CommU" ve "Sota" olmak üzere iki yeni tür masa üstü robot geliştirmiştir. $\mathrm{Bu}$ robotlar, bir konuşmada hangi katılımcılarla konuştuklarını ifade edebilir. Robotlar ayrıca diğer katılımcıları dinlediklerini düşündüren "sosyal davranışlar" da sergileyebilir.

Teknolojiyi bu kadar ilginç kılan, bir gruptaki bu robotlar arasındaki önceden programlanmış etkileşimdir. $\mathrm{Bu}$ nedenle, onları üç veya dört kişilik çiftler veya gruplar halinde satın almak gerekir. Robotlar, bir dizi konuda birbirleriyle "konuşmak" üzere programlanmıştır; uzaktan bakıldığında, gerçek bir konuşma gerçekleşiyor gibi görünmektedir. Grup bir insanın varlığını algıladığında, onlarla ilişki kurmaya ve onları iletişim kurmaya teşvik etmeye programlanmıştır. CommU tarafından bir insanla gerçekçi bir şekilde etkileşim kurmak için kullanılan çeşitli sözlü yönlendirmelerin yanı sıra, herhangi bir konuşmayı gerçek hissettirmek için önemli olan, göz yuvarlamak gibi bazı temel vücut dili özelliklerini de içermektedir. "CommU”nun gözlerinde, başında ve gövdesinde, çeşitli bakış temsillerine olanak tanıyan bol miktarda serbestlik vardır. Konuşma hissi verme yeteneği buna dayanmaktadır. Robot, diğer robotlar arasındaki konuşma sırasında zaman zaman katılımcıya bir soru sorabilir veya onay isteyebilir, böylece katılımcı sohbet duygusunu hisseder.

"Sota", "CommU”nun araştırma sonuçlarına dayanan ve Sosyal Sohbet Robotlarını yaygınlaştırmak amacıyla geliştirilmiş bir robot platformudur. "CommU"dan daha basit bir mimariye sahip ve evde kullanılmak üzere bir robot yaratıcısı Tomotaka Takahashi tarafından tasarlanmıştır.

Alan yazında yer alan bir araştırmada (Shimaya vd., 2019) düşüncelerin ve endişelerin sözlü olarak açıklanmasını kolaylaştırmak için tele-operasyonlu bir robot kullanmanın avantajları incelenmiştir. Bir saha çalışmasında, sosyal etkileşimde sıklıkla engellerle karşılaşan otizm spektrum bozukluğu olan bireylere, bakıcıları tarafindan tele-operasyonlu bir robot olan CommU tarafından günlük yaşam rehberliği sağlanmıştır. Robotun uzaktan veya aynı odadan çalıştırıldığ durumlarda, denekler daha önce bakıcılarına açıklamadıkları endişelerini robota açıklayabilmişlerdir.

\subsection{QTrobot}

QTrobot, çocuklar ve ebeveynleri arasında aktif ve ilgili bir etkileşimi teşvik ederek özel gereksinimli bireylere verilen eğitiminin etkililiğini artırmak için tasarlanmış etkileyici bir sosyal robottur. QTrobot, çeşitli yaşam becerilerini öğretmek ve uygulamak için çocukların dikkatini çeken samimi ve etkili bir kurulum sağlamaktadır. Bilişsel, sosyal, iletişim ve konuşma 
becerileri için yüzün üzerinde tutarlı ve kapsamlı öğretim modülü ile iyi tasarlanmış bir müfredat sunmaktadır.

QTrobot otizm spektrum bozukluğu olan çocuklara iletişim ve sosyal beceriler hakkında bilgi vermek için yüz ifadeleri, jestler ve oyunlar kullanmaktadır. Etkileyici robot, dil ve iletişim becerileri, sosyal beceriler ve bilişsel becerileri kapsayan sonsuz bir dizi öğrenme programı sunmaktadır. Programlar, oyunların karmaşıklığını ve zorluğunu kademeli olarak artırırken, çocuğun mevcut beceri düzeyinde öğretmeye başlayacak şekilde tasarlanmıştır.

Bilimsel ve deneysel çalı̧malar, QTrobot'un özel gereksinimli bireylerde dikkati ve motivasyonu artırdığını, kaygıyı ve dikkat dağınıklığını azalttığını göstermektedir (Papakostas ve ark., 2021). Alan yazında otizm spektrum bozukluğu olan çocuklara yönelik müdahalelerde, çocukların dikkatlerini, taklitlerini, tekrarlayan ve kalıplaşmış davranışların varlığını değerlendirerek, sosyal yardım sağlayan bir robot olan QTrobot'un kullanışlılığını değerlendirmek amacıyla bir araştırma yapılmıştır (Costa ve ark., 2018). Yaşları 4 ile 14 arasında değişen, otizm spektrum bozukluğu tanısı almış on beş çocuk, biri bir insanla diğeri robotla olmak üzere iki kısa etkileşime katılmıştır. Çocuklar insandan çok robota daha fazla ilgi göstermişlerdir. Ayrıca, araştırmada çocukların robotu insan kadar taklit ettikleri ve robotla insana göre daha az tekrarlayan veya kalıplaşmış davranışlarda bulundukları ifade edilmiştir. $\mathrm{Bu}$ araştırma bulguları, otizm spektrum bozukluğu olan çocuklarla kısa etkileşimlerde robotların faydalı ve çocukların öğrenmesini etkileyebilecek tekrarlayan ve basmakalıp davranışları azaltmada robotların kullanışlı olduğunu göstermektedir.

\subsection{KineTron}

KineTron bir çocuğun motor becerilerine olan ilgisini artırmak ve onu cesaretlendirmek için bir koç gibi davranan insans1 bir sosyal robottur. "KineTron", ticari olarak satılan Bioloid Premium robotik kitinden oluşturulmuştur. Ses ve müzikle birleştirilmiş robot davranışının dokuz hareket senaryosu geliştirilmiş̧ir. Eğitim seansı sırasında, bir terapist uzaktan kumandadaki bir düğmeye basarak senaryolardan birini etkinleştirmektedir.

Rehabilitasyon Robotunun değerlendirilmesi amacıyla 4-9 yaşları arasında serebral palsi'li altı kişilik bir grup çocuk üzerinde yapılan bir araştırma çocukların motor eğitiminde insansı robotların kullanılmasının potansiyel faydaları olduğunu öne sürmektedir (Kozyavkin ve ark., 2014). Ayrıca KineTron çocukları motive etmekte ve rehabilitasyon faaliyetlerine aktif katılımı teşvik etmektedir.

Yukarıda detaylı bir şekilde sunulan insansı robotların yanı sira Rero, FACE, Robovie R3, Troy, Pepper, ve Milo adlı özel eğitimde sıklıkla kullanılan insansı robotlar da bulunmaktadır. Şekil 1'de özel eğitimde sıklıkla kullanılan insansı robotlar gösterilmektedir. 


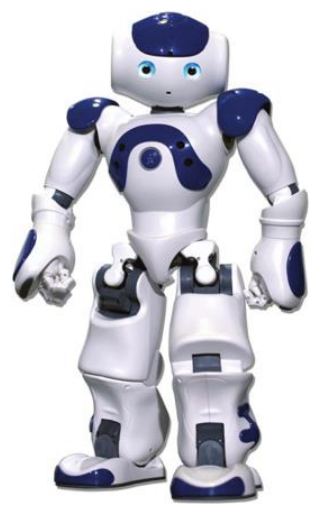

Nao

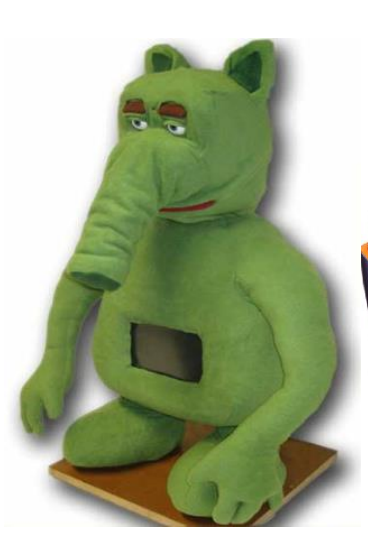

Probo

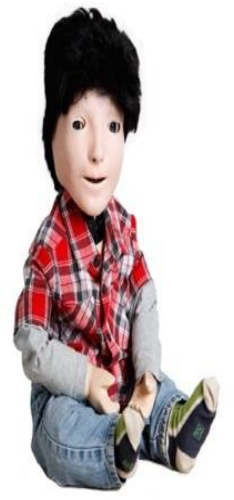

Kaspar

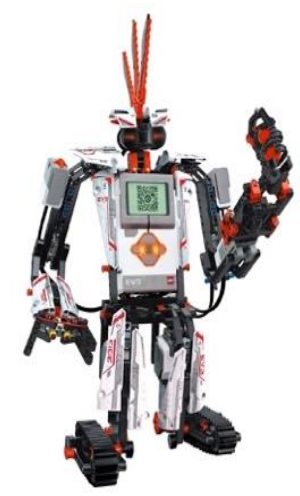

Lego-Mindstorms-ev3



iRobiQ

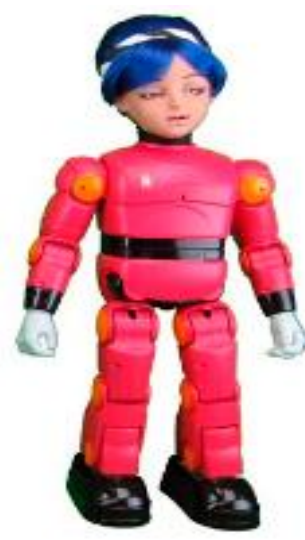

Alice

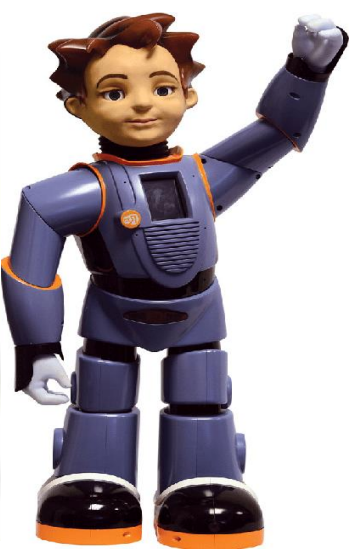

Zeno

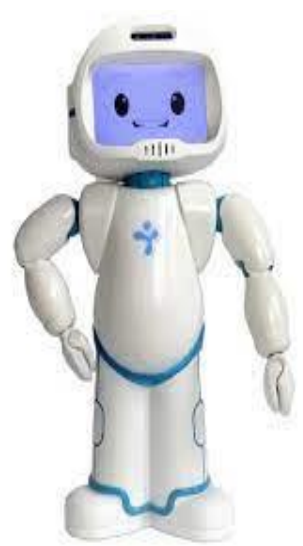

QTrobot



CommU ve Sota

Şekil 1. Özel Eğitimde Kullanılan İnsansı Robot Türleri

\section{Sonuç}

$\mathrm{Bu}$ çalışmada genel eğitimde ve özel eğitimde robotların kullanımı ile özel gereksinimli bireylerde sıklıkla kullanılan insansı robotlar üzerine odaklanılmıştır. Özel eğitim alanında insansı robotlar kullanılarak yapılan bazı araştırmaların bulgularına da yer verilmiştir. Ayrıca insansı robotların eğitimde kullanımına ilişkin uygulama ve çalışmaların gözden geçirilmesi yoluyla, insans1 robotların uygulama/hizmetlerinde umut verici bir alan olarak eğitim ekosisteminde robot kullanımına dikkat çekilmiştir.

Eğitimde kullanılan insansı robotların artışına paralel olarak özel eğitimde de bu robotların artan bir şekilde kullanıldığı görülmektedir. Güncel bir derleme çalışmasında dünya genelinde 99 çalışmada insansı robotların özel eğitimde kullanıldığ vurgulanmıştır (Papakostas, 2021). Bu çalışmaların büyük çoğunluğunun otizm spektrum bozukluğu olan bireyler üzerinde gerçekleştirildiği görülmektedir. $\mathrm{Bu}$ nedenle bazı derleme çalışmaları (ör. İsmail vd., 2019) sadece otizmli bireylerin eğitiminde kullanılan çalışmaları sentezlemiştir. Buradan hareketle özel eğitimde insansı robotların henüz istenilen seviyede olmadığı ayrıca farklı yetersizliği olan bireylerde daha çok uygulama yapılması gerektiği sonucu çıkarılabilir. Otizm spektrum bozukluğu, zihinsel yetersizliği, dil ve konuşma bozukluğu ve fiziksel yetersizliği olan çocuklara robot kullanılarak başarılı müdahalelerde bulunulduğu açıktır (Syriopoulou-Delli ve Gkiolnta, 2021). Örneğin zihinsel yetersizliği olan bireylerin hayatlarını kolaylaştıracak ve öğrenmelerine yardımcı olabilecek birçok insansı robot mevcutken bu tür engel gruplarında çok az çalışma yapıldığı literatürde sıklıkla belirtilmektedir (Özdemir ve ark., 2015).

İnsansı robotların özel eğitimde kullanılmasının faydaları, analiz edilen çalışmalardan açıkça görülmektedir. Ancak robotların maliyeti, öğretmenler için fazladan çalışma, çözülmesi gereken teknik ve bilimsel sorunlar ile uzun vadeli etkilerinin neler olduğu gibi hala keşfedilecek ve cevaplanacak sorular bulunmaktadır. Teknik çözümleri ve pedagojik avantajları doğrulamak için daha fazla araştırmaya ihtiyaç duyulduğu açıktır. Ayrıca disiplinlerarası teknik ve teknolojilerin kombinasyonu insansı robot eğitim uygulamaları için yeni yollar açabilir. Özellikle FeTeMM (Fen, teknoloji, mühendislik ve matematik) gibi çok disiplinli alanlarda daha çok uygulanan insansı robotların özel eğitimde de disiplinler arası etkinliklerde kullanılması düşünülebilir. 
İnsansı robotların eğitimde kullanılması pedagojik ve etik bir bakış açısı ile de değerlendirilmektedir. "Öğrenciler için ögrenmeyi kolaylaştırmaya devam etmek uygun mudur?", "Çaba harcamadan öğrenmek mümkün ve kabul edilebilir olacak mı?" gibi sorular akla gelmektedir. Bu sorular, robotların eğitimdeki rolünün tam olarak ne olması gerektiğini tanımlamaya yardımcı olacaktır. Ancak, herkesin robotların çalışma şekli hakkında asgari düzeyde bir anlayışa sahip olması, gelişimlerini takip etmesi ve toplumda kendileri için uygun yerleri bulması önemlidir.

\section{Kaynakça}

Akalin, N., Uluer, P., Kose, H., \& Ince, G. (2013, November). Humanoid robots communication with participants using sign language: An interaction based sign language game. In 2013 IEEE workshop on advanced robotics and its social impacts (pp. 181-186). IEEE.

Alemi, M., Meghdari, A., \& Ghazisaedy, M. (2015). The impact of social robotics on L2 learners' anxiety and attitude in English vocabulary acquisition. International Journal of Social Robotics, 7(4), 523-535.

Alimisis, D., \& Kynigos, C. (2009). Constructionism and robotics in education. In TERECoP Project: Teacher education on roboticsenhanced constructivist pedagogical methods. Athens, GR: School of Pedagogical and Technological Education, ASPETE.,pp. 11-26.

Alkhalifah, A., Alsalman, B., Alnuhait, D., Meldah, O., Aloud, S., Al-Khalifa, H. S., \& Al-Otaibi, H. M. (2015, July). Using NAO humanoid robot in kindergarten: a proposed system. In 2015 IEEE 15th International Conference on Advanced Learning Technologies (pp. 166-167). IEEE.

Barakova, E. I., Bajracharya, P., Willemsen, M., Lourens, T., \& Huskens, B. (2015). Long-term LEGO therapy with humanoid robot for children with ASD. Expert Systems, 32(6), 698-709.

Belpaeme, T., Kennedy, J., Ramachandran, A., Scassellati, B., \& Tanaka, F. (2018). Social robots for education: A review. Science robotics, 3(21). URL http://robotics.sciencemag.org/content/3/21/eaat5954

Chang, C. W., Lee, J. H., Chao, P. Y., Wang, C. Y., \& Chen, G. D. (2010). Exploring the possibility of using humanoid robots as instructional tools for teaching a second language in primary school. Journal of Educational Technology \& Society, 13(2), 13-24.

Chase, C. C., Chin, D. B., Oppezzo, M. A., \& Schwartz, D. L. (2009). Teachable agents and the protégé effect: Increasing the effort towards learning. Journal of Science Education and Technology, 18(4), 334-352.

Chin, K. Y., Wu, C. H., \& Hong, Z. W. (2011, May). A humanoid robot as a teaching assistant for primary education. In 2011 Fifth International Conference on Genetic and Evolutionary Computing (pp. 21-24). IEEE.

Costa, A. P., Charpiot, L., Lera, F. R., Ziafati, P., Nazarikhorram, A., Van Der Torre, L., \& Steffgen, G. (2018, August). More attention and less repetitive and stereotyped behaviors using a robot with children with autism. In 2018 27th IEEE
International Symposium on Robot and Human Interactive Communication (RO-MAN) (pp. 534-539). IEEE.

Costa, S., Santos, C., Soares, F., Ferreira, M., \& Moreira, F. (2010, August). Promoting interaction amongst autistic adolescents using robots. In 2010 Annual International Conference of the IEEE Engineering in Medicine and Biology (pp. 3856-3859). IEEE.

Curto, B., \& Moreno, V. (2016). Robotics in education. Journal of Intelligent \& Robotic Systems, 81(1), 3-4.

Deshmukh, A., Jones, A., Janarthanam, S., Foster, M. E., Ribeiro, T., Corrigan, L. J., ... \& Castellano, G. (2015, March). Empathic robotic tutors: map guide. In Proceedings of the Tenth Annual ACM/IEEE International Conference on Human-Robot Interaction Extended Abstracts (pp. 311-311).

Edwards, C., Edwards, A., Spence, P. R., \& Lin, X. (2018). I, teacher: using artificial intelligence (AI) and social robots in communication and instruction. Communication Education, 67(4), 473-480.

García-Peñalvo, F. J., Conde, M. Á., Gonçalves, J., \& Lima, J. (2019, October). Computational thinking and robotics in education. In Proceedings of the Seventh International Conference on Technological Ecosystems for Enhancing Multiculturality (pp. 2-5).

Ghallab, M., \& Ingrand, F. (2020). Robotics and artificial intelligence. a guided tour of artificial intelligence research: Volume III: Interfaces and Applications of Artificial Intelligence, 389.

Han, J. H., Jo, M. H., Jones, V., \& Jo, J. H. (2008). Comparative study on the educational use of home robots for children. Journal of Information Processing Systems, 4(4), 159-168.

Hockstein, N. G., Gourin, C. G., Faust, R. A., \& Terris, D. J. (2007). A history of robots: from science fiction to surgical robotics. Journal of Robotic Surgery, 1(2), 113-118.

Huijnen, C. A., Lexis, M. A., \& de Witte, L. P. (2016). Matching robot KASPAR to autism spectrum disorder (ASD) therapy and educational goals. International Journal of Social Robotics, 8(4), 445-455.

Huskens, B., Verschuur, R., Gillesen, J., Didden, R., \& Barakova, E. (2013). Promoting question-asking in school-aged children with autism spectrum disorders: Effectiveness of a robot intervention compared to a human-trainer intervention. Developmental neurorehabilitation, 16(5), 345-356.

Iacono, I., Lehmann, H., Marti, P., Robins, B., \& Dautenhahn, K. (2011, August). Robots as social mediators for children with Autism-A preliminary analysis comparing two different robotic platforms. In 2011 IEEE international conference on development and learning (ICDL) (Vol. 2, pp. 1-6). IEEE.

Ismail, L. I., Verhoeven, T., Dambre, J., \& Wyffels, F. (2019). Leveraging robotics research for children with autism: a review. International Journal of Social Robotics, 11(3), 389410.

Johnson, J. (2003). Children, robotics, and education. Artificial Life and Robotics, 7(1-2), 16-21.

Jordan, K., King, M., Hellersteth, S., Wirén, A., \& Mulligan, H. (2013). Feasibility of using a humanoid robot for enhancing attention and social skills in adolescents with autism 
spectrum disorder. International Journal of Rehabilitation Research, 36(3), 221-227.

Kanda, T., Hirano, T., Eaton, D., \& Ishiguro, H. (2004). Interactive robots as social partners and peer tutors for children: A field trial. Human-Computer Interaction, 19(12), 61-84.

Kandlhofer, M., \& Steinbauer, G. (2014, July). Evaluating the impact of robotics in education on pupils'skills and attitudes. In Proceeding of the 4th International Workshop Teaching Robotics. Teaching with Robotics \& 5th International Conference Robotics in Education (pp. 101-9).

Kozyavkin, V., Kachmar, O., \& Ablikova, I. (2014, May). Humanoid social robots in the rehabilitation of children with cerebral palsy. In Proceedings of the 8th International Conference on Pervasive Computing Technologies for Healthcare (pp. 430-431).

Köse, H., Uluer, P., Akalın, N., Yorganc1, R., Özkul, A., \& Ince, G. (2015). The effect of embodiment in sign language tutoring with assistive humanoid robots. International Journal of Social Robotics, 7(4), 537-548.

Kubilinskienė, S., Žilinskienė, I., Dagienė, V., \& Sinkevičius, V. (2017). Applying robotics in school education: A systematic review. Baltic journal of modern computing, 5(1), 50-69.

Lee, H., \& Hyun, E. (2015). The intelligent robot contents for children with speech-language disorder. Journal of Educational Technology \& Society, 18(3), 100-113.

Lewis, L., Charron, N., Clamp, C., \& Craig, M. (2016). Co-robot therapy to foster social skills in special need learners: three pilot studies. In Methodologies and Intelligent Systems for Technology Enhanced Learning (pp. 131-139). Springer, Cham.

Lin, P., Abney, K., \& Bekey, G. (2011). Robot ethics: Mapping the issues for a mechanized world. Artificial Intelligence, 175(5-6), 942-949.

Lindsay, S., \& Hounsell, K. G. (2017). Adapting a robotics program to enhance participation and interest in STEM among children with disabilities: a pilot study. Disability and Rehabilitation: Assistive Technology, 12(7), 694-704.

López-Belmonte, J., Segura-Robles, A., Moreno-Guerrero, A. J., \& Parra-González, M. E. (2021). Robotics in education: a scientific mapping of the literature in web of science. Electronics, 10(3), 291.

Lytridis, C., Vrochidou, E., Chatzistamatis, S., \& Kaburlasos, V. (2018, June). Social engagement interaction games between children with Autism and humanoid robot NAO. In The 13th international conference on soft computing models in industrial and environmental applications (pp. 562-570). Springer, Cham.

Masson, O., Baratgin, J., Jamet, F., Ruggieri, F., \& Filatova, D. (2016, July). Use a robot to serve experimental psychology: Some examples of methods with children and adults. In 2016 International Conference on Information and Digital Technologies (IDT) (pp. 190-197). IEEE.

Miller, D. P., Nourbakhsh, I. R., \& Siegwart, R. (2008). Robots for Education. Springer handbook of robotics, 1283, 1301.
Mubin, O., Stevens, C. J., Shahid, S., Al Mahmud, A., \& Dong, J. J. (2013). A review of the applicability of robots in education. Journal of Technology in Education and Learning, 1(2090015), 1-7.

Mwangi, E., Diaz, M., Barakova, E., Catala, A., \& Rauterberg, M. (2017, October). Can children take advantage of nao gazebased hints during gameplay?. In Proceedings of the 5th international conference on human agent interaction (pp. 421424).

Pachidis, T., Vrochidou, E., Kaburlasos, V. G., Kostova, S., Bonković, M., \& Papić, V. (2018, June). Social robotics in education: State-of-the-art and directions. In International Conference on Robotics in Alpe-Adria Danube Region (pp. 689-700). Springer, Cham.

Palestra, G., Varni, G., Chetouani, M., \& Esposito, F. (2016, November). A multimodal and multilevel system for robotics treatment of autism in children. In Proceedings of the International Workshop on Social Learning and Multimodal Interaction for Designing Artificial Agents (pp. 1-6).

Pandey, A. K., \& Gelin, R. (2017). Humanoid robots in education: a short review. Humanoid robotics: a reference, 1-16.

Papakostas, G. A., Sidiropoulos, G. K., Papadopoulou, C. I., Vrochidou, E., Kaburlasos, V. G., Papadopoulou, M. T., ... \& Dalivigkas, N. (2021). Social Robots in Special Education: A Systematic Review. Electronics, 10(12), 1398.

Pop, C. A., Simut, R., Pintea, S., Saldien, J., Rusu, A., David, D., ... \& Vanderborght, B. (2013). Can the social robot Probo help children with autism to identify situation-based emotions? A series of single case experiments. International Journal of Humanoid Robotics, 10(03), 1350025.

Pour, A. G., Taheri, A., Alemi, M., \& Meghdari, A. (2018). Human-robot facial expression reciprocal interaction platform: case studies on children with autism. International Journal of Social Robotics, 10(2), 179-198.

Rakhymbayeva, N., Seitkazina, N., Turabayev, D., Pak, A., \& Sandygulova, A. (2020, March). A long-term study of robotassisted therapy for children with severe autism and ADHD. In Companion of the 2020 ACM/IEEE International Conference on Human-Robot Interaction (pp. 401-402).

Robins, B., Dautenhahn, K., Te Boekhorst, R., \& Billard, A. (2005). Robotic assistants in therapy and education of children with autism: can a small humanoid robot help encourage social interaction skills?. Universal Access in The Information Society, 4(2), 105-120.

Shimaya, J., Yoshikawa, Y., Kumazaki, H., Matsumoto, Y., Miyao, M., \& Ishiguro, H. (2019). Communication support via a tele-operated robot for easier talking: case/laboratory study of individuals with/without autism spectrum disorder. International Journal of Social Robotics, 11(1), 171-184.

Silva, V., Soares, F., Esteves, J. S., \& Pereira, A. P. (2018, November). Building a hybrid approach for a game scenario using a tangible interface in human robot interaction. In Joint International Conference on Serious Games (pp. 241-247). Springer, Cham.

Silvera-Tawil, D., Bradford, D., \& Roberts-Yates, C. (2018, August). Talk to me: The role of human-robot interaction in improving verbal communication skills in students with 
autism or intellectual disability. In 2018 27th IEEE International Symposium on Robot and Human Interactive Communication (RO-MAN) (pp. 1-6). IEEE.

Simut, R. E., Vanderfaeillie, J., Peca, A., Van de Perre, G., \& Vanderborght, B. (2016). Children with autism spectrum disorders make a fruit salad with Probo, the social robot: an interaction study. Journal of autism and developmental disorders, 46(1), 113-126.

Syriopoulou-Delli, C., \& Gkiolnta, E. (2021). Robotics and inclusion of students with disabilities in special education. Research, Society and Development, 10(9), e36210918238e36210918238.

Taheri, A. R., Alemi, M., Meghdari, A., PourEtemad, H. R., \& Basiri, N. M. (2014, October). Social robots as assistants for autism therapy in Iran: Research in progress. In 2014 Second RSI/ISM International Conference on Robotics and Mechatronics (ICRoM) (pp. 760-766). IEEE.

Taheri, A., Meghdari, A., Alemi, M., \& Pouretemad, H. (2018). Human-robot interaction in autism treatment: a case study on three pairs of autistic children as twins, siblings, and classmates. International Journal of Social Robotics, 10(1), 93-113.

Taheri, A., Meghdari, A., Alemi, M., \& Pouretemad, H. (2019). Teaching music to children with autism: a social robotics challenge. Scientia Iranica, 26(Special Issue on: SocioCognitive Engineering), 40-58.

Taheri, A., Meghdari, A., Alemi, M., Pouretemad, H., Poorgoldooz, P., \& Roohbakhsh, M. (2016, November). Social robots and teaching music to autistic children: myth or reality?. In International conference on social robotics (pp. 541-550). Springer, Cham.

Tanaka, F., \& Matsuzoe, S. (2012). Children teach a carereceiving robot to promote their learning: Field experiments in a classroom for vocabulary learning. Journal of HumanRobot Interaction, 1(1), 78-95.

Tuna, G., Tuna, A., Ahmetoglu, E., \& Kuscu, H. (2019). A survey on the use of humanoid robots in primary education: Prospects, research challenges and future research directions. Cypriot Journal of Educational Sciences, 14(3), 361-373.

van den Heuvel, R. J., Lexis, M. A., \& de Witte, L. P. (2017). Robot ZORA in rehabilitation and special education for children with severe physical disabilities: a pilot study. International journal of rehabilitation research. Internationale Zeitschrift fur Rehabilitationsforschung. Revue internationale de recherches de readaptation, 40(4), 353.

Van Der Drift, E. J., Beun, R. J., Looije, R., Henkemans, O. A. B., \& Neerincx, M. A. (2014, March). A remote social robot to motivate and support diabetic children in keeping a diary. In 2014 9th ACM/IEEE International Conference on HumanRobot Interaction (HRI) (pp. 463-470). IEEE.

Vanderborght, B., Simut, R., Saldien, J., Pop, C., Rusu, A. S., Pintea, S., ... \& David, D. O. (2012). Using the social robot probo as a social story telling agent for children with ASD. Interaction Studies, 13(3), 348-372.

Westlund, J. K., Dickens, L., Jeong, S., Harris, P., DeSteno, D., \& Breazeal, C. (2015). A comparison of children learning new words from robots, tablets, \& people. In Proceedings of the 1st international conference on social robots in therapy and education.

Wood, L. J., Robins, B., Lakatos, G., Syrdal, D. S., Zaraki, A., \& Dautenhahn, K. (2019). Developing a protocol and experimental setup for using a humanoid robot to assist children with autism to develop visual perspective taking skills. Paladyn, Journal of Behavioral Robotics, 10(1), 167179.

Yadollahi, E., Johal, W., Paiva, A., \& Dillenbourg, P. (2018, June). When deictic gestures in a robot can harm child-robot collaboration. In Proceedings of the 17th ACM Conference on Interaction Design and Children (pp. 195-206).

Yolcu, V., \& Demirer, V. (2017). A review on the studies about the use of robotic technologies in education. SDU International Journal of Educational Studies, 4(2), 127-139. 